\title{
A Numerical Study of a Cooling Ratio for Laser Based Prototyping Technology with a Sample of 3161 Stainless Steel
}

\author{
R.S. Amano*, Z. Xu, J. Martinez Lucci and Pradeep Rohatgi
}

Department of Mechanical Engineering, University of Wisconsin-Milwaukee, USA

\begin{abstract}
The objectives of this work are to study Laser Engineered Net Shaping (LENS ${ }^{\mathrm{TM}}$ ) produced materials and identify the microstructures. Numerical method was used to examine the influence of materials' type and LENS ${ }^{\mathrm{TM}}$ process parameters on the forming of the specific microstructures from thermodynamics and fluid dynamics point of view. Samples of $316 \mathrm{~L}$ stainless steel were examined, microstructures of samples were used to estimate the corresponding cooling rate, and the cooling rate was compared with the results of three different levels of simplified models.
\end{abstract}

Keywords: Computational Fluid Dynamics, Manufacturing, Solidification, Melting, Metals.

\section{INTRODUCTION}

LENS $^{\mathrm{TM}}$ is a type of Rapid Prototyping (RP) technology, that is unique in fabricating fully dense metal parts directly from Computer Aided Design (CAD) solid models by layer additive methods [1]. The thermal history plays an important role in this process, particularly; the heating and cooling history are the critical factors to determine the microstructure of the produced part. LENS has been employed since 1970s. Anthony\& Cline [2] published a paper whose main objective is to improve surface finish by showing how to calculate the velocity of scanning - moving part. Moving the part faster than critical speed will cause avoidance of rippling - wavy effect, which causes rough surface. Although this paper analyzes two-step laser cladding process - depositing the powder, and then melting it, rather than one-step LENS ${ }^{\mathrm{TM}}$ process (when depositing and melting are done simultaneously), findings are useful for LENS $^{\mathrm{TM}}$, too. Laser-beam impact point and the intersection line of the solid-liquid interface with the surface generate surface-tension gradients that sweep liquid away from beam impact point. The resulting flow of liquid creates a depression of the liquid surface beneath the beam and ridging of the liquid surface elsewhere. As the beam passes to other areas of the surface, this distortion of the liquid is being frozen, thus creating a roughened rippled surface. If the traverse speed is higher than critical velocity, the liquid does not have sufficient time to form ripples - rippling from surface-tension gradients can be avoided.

Kamotani \& Ostrach [3] analyzed thermocapillary flow. Thermocapillary flow is the flow caused by heat-induced surface tension variations along a free, liquid surface. Convection is represented by Marangoni number (Ma). Thermocapillary flow transits to oscillatory flow at the critical value of $\mathrm{Ma}\left(\sim 6 \times 10^{4}\right)$. Oscillatory mechanism has been

\footnotetext{
*Address correspondence to this author at the Department of Mechanical Engineering, University of Wisconsin-Milwaukee; Tel: 414-229-2345;

E-mail:amano@uwm.edu
}

explored in space laboratory, where 1-G effect from the experiments on the earth can be neglected. Results were presented in the second listed paper; however, the use of just Ma to specify the onset of oscillations was not appropriate.

According to Kobryn et al. [4], there are two types of porosity: 1) lack-of-fusion (LOF) porosity (caused by incomplete melting of substrate or previous layer; along layer boundaries; irregularly shaped; at thin substrates), and 2) gas porosity (caused by gas from the powder feed entrapment; at thicker substrates). Both types of porosity decrease with increase of traverse speed and power level. Liu and DuPont [5] reported that LENS ${ }^{\mathrm{TM}}$ is convenient for metals and alloys: H13, 316 stainless steel, nickel-base superalloys and titanium alloys. A problem in depositing alloys by LENS cracks in the deposits. Cooling rate is dependent upon the heat input $(\mathrm{P} / \mathrm{V})$. Preheating substrate to $450-500^{\circ} \mathrm{C}$ is necessary to prevent the solid-state cracking.

Boddu et al. [6] developed an empirical model for explaining Laser Based Manufacturing Technique (LAMT) processes. RP has an ability to fabricate complex metal parts. Monitoring of the Direct Material Deposition (DMD) process is done by: laser displacement sensor, temperature sensor and CCD matrix camera. Processes like: laser cladding, laser forming, laser ablation, laser welding, laser surface treatment, laser metal deposition require certain factors to be monitored: powder feeder, energy delivery - heat input, powder utilization efficiency, dilution (determines the amount of liquid layer that needs to be formed on the substrate to ensure proper bonding), depth-relation (penetration depth increases almost linearly with increase in the specific energy), porosity (occurs due to cavities between tracks that form from overlapped tracks; clad' aspect ratio width/height - should be $>5$ and percentage overlap $<70 \%$ ), clad dimensions, powder catchment efficiency, etc. and fitting these factors into models.

According to Brooks et al. [7], advantages of LENS ${ }^{\mathrm{TM}}$ process are: real time control of microstructure, tailored material properties at different part locations, the production of graded structures, etc. Complex thermal history occurs dur- 
ing LENS ${ }^{\mathrm{TM}}$ process. Microstructure is determined by using transmission electron microscopy (TEM) - un-tempered martensite structure is at the supercritical region.

According to Pan et al. [8], advantages of semi-solid processing to near-net shaping are: reduced turbulence in the die cavity, reduced defects, better mechanical properties than high-pressure die castings, reduced die wear, lower energy consumption. AlB2 alloy was examined. Two major types of semi-solid processes are: 1) thixocasting; 2) rheocasting.

Atwood [9] shows that "high temperatures make it hard to form accurate, smooth objects from molten metal" - the problem with dimensional accuracy - finished product has slightly corrugated surface. Ability to mix powder streams of different materials is pointed out.

Gatto et al. [10] conducted experiments in order to improve Z-Cast technique - metal casting process (in this case - Al alloy) and apply it in automotive industry. Special attention was paid on evaluating eventual critical factors in the technological chain. Obtained results were satisfactory deviations wise.

Henning et al. [11] had a goal to identify the potentials of Rapid manufacturing (RM) process chains and their flexible structuring, as well as to select proper application, in the light of increasing need for individualization of products. As early stage of RP, conception, development and productprototyping are defined. Future directions in research are: $100 \%$ quality control of individual mass products, smoother and more accurate surfaces, materials and combination of materials, logistics. Software used for surface modeling, geometrical inspection, analysis of flaws, material inhomogeneity or material structures.

Syed et al. [12] did experimental comparison between parameters for the wire and powder metal deposition. For the powder, overlap of clads was $30^{\circ}$. Surface was rougher for powder feeding. Powder was fed through different nozzle than inert gas; any angle between $0-180^{\circ}$ was satisfactory. There was no significant difference in microstructure - samples remained austenitic. Cavities between adjacent overlapped layers were present. Deposition efficiency was far worse for the powder; deposition rate increased with $\mathrm{CO}_{2}$ laser power increase. Undulation of the surface was caused partly by loose particles, embedded particles and semimolten particles, and partly by the instability of the molten pool - the number, size and shape of the powder particles entering the melting pool at any point are not constant. Also, generally stronger gas flow in the center of the pool due to atomizing gas can also disturb the pool. 3-D heat transfer at the layer with fine microstructure near the substrate becomes 2-D and with coarser microstructure further from.

Grujicic et al. [13] developed a model for in-flight melting of metal powder in LENS ${ }^{\mathrm{TM}}$. In addition, optimization analysis is performed. Results show that as particle velocity decreases and particle trajectory angle (between particle and laser beam) decreases, residence time of particles in the laser beam increases. Short description of LENS ${ }^{\mathrm{TM}}$ system is given. Oxygen level in the glove box is maintained bellow 23 ppm. The important difference between two basic LENS ${ }^{\mathrm{TM}}$ modes is made: 1) the focus of the laser is on the substrate, making melting pool where the metal powder is injected; 2) metal powder is injected at the focus of the laser that is above the substrate - melting substrate has to be avoided (considered in this work). Energy necessary to melt metal particles is calculated. Optimization method (laser power) increases particle size from $27 \mu \mathrm{m}$ to $300 \mu \mathrm{m}$. Laser-power threshold for substrate melting decreases when trajectory angle increases - if the trajectory angle increases, focus of the laser beam needs to be closer to the substrate. Also, melting of the substrate surface is modeled (2D) and it uses Gaussian distribution for the laser power.

Hofmeister et al. [14] used thermal imaging and metallographic analysis to control cooling rates in LENS ${ }^{\mathrm{TM}}$ process. Heat transfer is modeled. Molten zone is $0.5-1.5 \mathrm{~mm}$ long, and cooling rates range from $200-6000 \mathrm{~K} / \mathrm{s}$. The key to the mechanical structure is the solidification structure. The net rate of material deposition is $2.2 \mathrm{~mm}^{3} / \mathrm{s}$, argon velocity is $30 \mathrm{~m} / \mathrm{s}$. The geometry and temperature of the substrate are the most important factors in determining the molten pool size, since about $90 \%$ of heat carried out of molten pool is conducted through the substrate. Heat conduction is the greatest for the first layer (depositing on a cold substrate) and therefore, the first layer has the smallest molten pool. Solidification is not a steady process; thermal gradients drive Marangoni convection. Re-melting and coarsening occurs subsequently to initial deposition. The primary phase formed in the solidification process is austenite. As the laser energy increases (absorbtivity of a material at the wavelength times $Q$ / travel velocity $V$ ) increases, molten pool size increases (both in $\mathrm{x}$ and $\mathrm{y}$ direction). The local minimum of gradient curves defines the dimensions of the molten zone. Cooling rate decreases when the laser power increases according to Rosenthal [15]. Finite element analysis is suitable for predicting the cooling rates during deposition. Freezing rate, the inverse of cooling rate, was found to be proportional to the square root of thickness. In this quasi-steady conditions, the square of the molten pool length should be inversely proportional to the cooling rate. Therefore, cooling rate can be approximated by knowing the length of the molten pool. Since the laser power can be controlled to achieve desired molten pool length, then cooling rate and consequently microstructure can be altered.

Liu \& DuPont [16] considered functionally graded materials (FGMs) - combining ceramic powder with metal powder in different ratios. Here, the LENS ${ }^{\mathrm{TM}}$ system, that usually consists of four systems (Nd:YAG laser, four nozzle coaxial powder system, controlled environment glove box and a motion controlled system) had a melt pool sensor (MPS), which constantly adjusts the laser power. Also, rotational speed for the powder is controlled. The laser absorption coefficient of a material is a function of temperature, electrical resistivity and laser's wavelength. By combining two types of materials; thermal stresses can be significantly reduced. Both cracks and plastic deformations can be reduced as well.

Watkins's [17] work discusses current research and prospects of Direct Laser Fabrication (DLF). Originally, laser cladding was used to improve wear and corrosion resistance of surface of metal parts through: 1) pre-placed, or 2) blown powder cladding. One of methods was computer controlled one or more feeder screws in each hopper. Hardness and wear maps were created. Out of three basic cross sections of 
clad tracks, low dilution fusion bonded track is the preferred cross section profile. In order to avoid porosity, aspect ratio (width/height of the clad) needs to be higher than 5. Aspect ratio decreases with thicker clad layer and higher mass flow rates. Dilution should be (5-10)\%.

According to Klingbeil et al. [18], laser welding has application in aerospace (and car) industry, with main advantage to significantly reduce buy-to-fly ratio. Predicting microstructure will help predicting mechanical properties. By the use of elemental blends, creating the next generation of aerospace materials is possible. The work enforces simulation-based methods, and reduces trial and error methods in order to predict the effects of process variables (laser power and laser velocity) on microstructure. Used numerical modeling procedures: 2-D thermal continuum finite element modeling (finite element software ABAQUS used to provide insight into the effects of variables on grain size and morphology; fraction of laser power absorbed by the deposit $\alpha=35 \%$; contour limit $1650^{\circ} \mathrm{C}$ ) and $3-\mathrm{D}$ cellular automation (used to provide direct predictions of microstructure in Ti6Al-4V; ProCast ${ }^{\mathrm{TM}}$ software used - Gaussian distribution of nucleation sites). Since CAFE3D software is designed to start from an entirely liquid state, it was necessary to first isolate the melt pool region from the ProCast ${ }^{\mathrm{TM}}$ model. Substrate: $50.4 \mathrm{~mm}(\mathrm{~L})$ x $8.69 \mathrm{~mm}(\mathrm{~W})$ x $2.26 \mathrm{~mm}(\mathrm{H})$; laser power: $(315$ - 385) W; laser velocity $(6.35-10.6) \mathrm{mm} / \mathrm{s}$. If the grain morphology is categorized: equiaxed, columnar, mixed; resulting microstructure was columnar. Fourier's Law was used to determine nodal heat flux output. Solidification velocity $(\mathrm{R})$ - cooling rate increases with increasing laser velocity.

In this paper, the microstructures of $\mathrm{LENS}^{\mathrm{TM}}$ produced 316L stainless steel and the microstructures were examined and the corresponding cooling rates were calculated using the experimental relations [19]. At the same time, the numerical results were compared with that of experiment.

\section{MATERIALS AND METHODOLOGY}

\section{Sample Study}

316L stainless steel block building sample is studied in this paper; the Dendritic Arm Spacing (DAS) was measured to be 3.7-5.38 microns. The calculated cooling rate for this sample using equation $\lambda_{1}=80(\varepsilon)^{-0.33}$ is $11000 \mathrm{~K} / \mathrm{s}$.

\section{Numerical Simulation}

When the substrate traverses under the laser, metals are melted for the closing up of laser spot and solidified for the parting away of laser spot. Simultaneously, powders are injected into the melting pool, there are following several phenomena involved: convection, conduction and radiation heat transfer; metal's melting and solidification, heat and mass exchange between discreet particle powders and continuum melting pool.

Navier-Stokes (N-S) equations are the governing equation for simulating the flow field and thermal field in and around the melting pool. In addition, Lagrange-Eulerian method is used to track the motion of powders and heat transfer between powders and melting pool. The Volume of Fluid (VOF) method was used to track the interface between liquid metal and environment gas, Argon. Mushy zone melting / solidification model is used to mark the interface of liquid metal and solidified metal.

\section{Mathematical Procedures}

The heat conduction equation is given by

$\frac{\partial(\rho c T)}{\partial t}=\nabla \bullet(k \nabla T)-\frac{\partial}{\partial t}\left(\rho L F_{l}\right)$

where $\rho$ is the density of the liquid mixture, $c$ is the mixture specific heat capacity, $k$ is the mixture conductivity, $L$ is the latent heat, and $F_{l}$ is the fraction of liquid solidified. The mixture properties are defined as

$$
\begin{aligned}
& \rho c=\left(1-F_{l}\right) \rho_{s} c_{s}+F_{l} \rho_{l} c_{l} \\
& k=\left(1-F_{l}\right) k_{s}+F_{l} k_{l}
\end{aligned}
$$

with the subscripts " $s$ " and "l" refer to the properties of the solid and liquid phase, respectively.

The discretized form of Eq. (1) can be written as

$a_{P} T_{P}^{n}=a_{P}^{o} T_{P}^{o}+\sum_{n b} a_{n b} T_{n b}^{n}-\left[F_{l P}^{n}-F_{l P}^{o}\right] \frac{\rho L}{\Delta t}$

where a's represent the numerical parameter given by Patankar [20], and the superscripts " $n$ " and " $o$ " refer to the current time iteration value and the previous time step value, respectively. Following Swaminathan and Voller's work [21], the liquid fraction at the current time step can be updated using

$F_{l P}^{k+1}=F_{l P}^{k}+\frac{d F_{l}}{d T}\left[T_{P}^{k+1}-T_{P}^{k}\right]$

where " $k$ " indicates the iteration count so that on convergence, the second term on the RHS of Eq. (5) is equal to zero. Direct substitution of Eq. (5) into Eq. (4), after dropping the iteration count superscript, yields

$\left[a_{P}-S_{P}\right] T_{P}^{n}=a_{P}^{0} T_{P}^{0}+\sum_{n b} a_{n b} T_{n b}^{n}+S_{C}$

$S_{P}=-\frac{\rho L}{\Delta t} \frac{d F_{l}}{d T}$

$S_{C}=\frac{\rho L}{\Delta t}\left[F_{l P}^{0}-F_{l P}^{n}+\frac{d F_{l}}{d T} T_{P}^{n}\right]$

The term $d F_{1} / d T$ can be evaluated according to the appropriate liquid fraction-temperature curve for the alloy. The curve following Scheil's equation used in this study is given in Appendix.

\section{Volume of Fluid (VOF) Method}

In LENS ${ }^{\mathrm{TM}}$ process, liquid metal is not penetrating with the environment gas, so the VOF model is suitable for this kind of situation. For each additional phase that was added to the model, a variable is introduced: the volume fraction of the phase in the computational cell. In each control volume, the volume fractions of all phases sum to unity. The fields for all variables and properties are shared by the phases and represent volume-averaged values, as long as the volume 


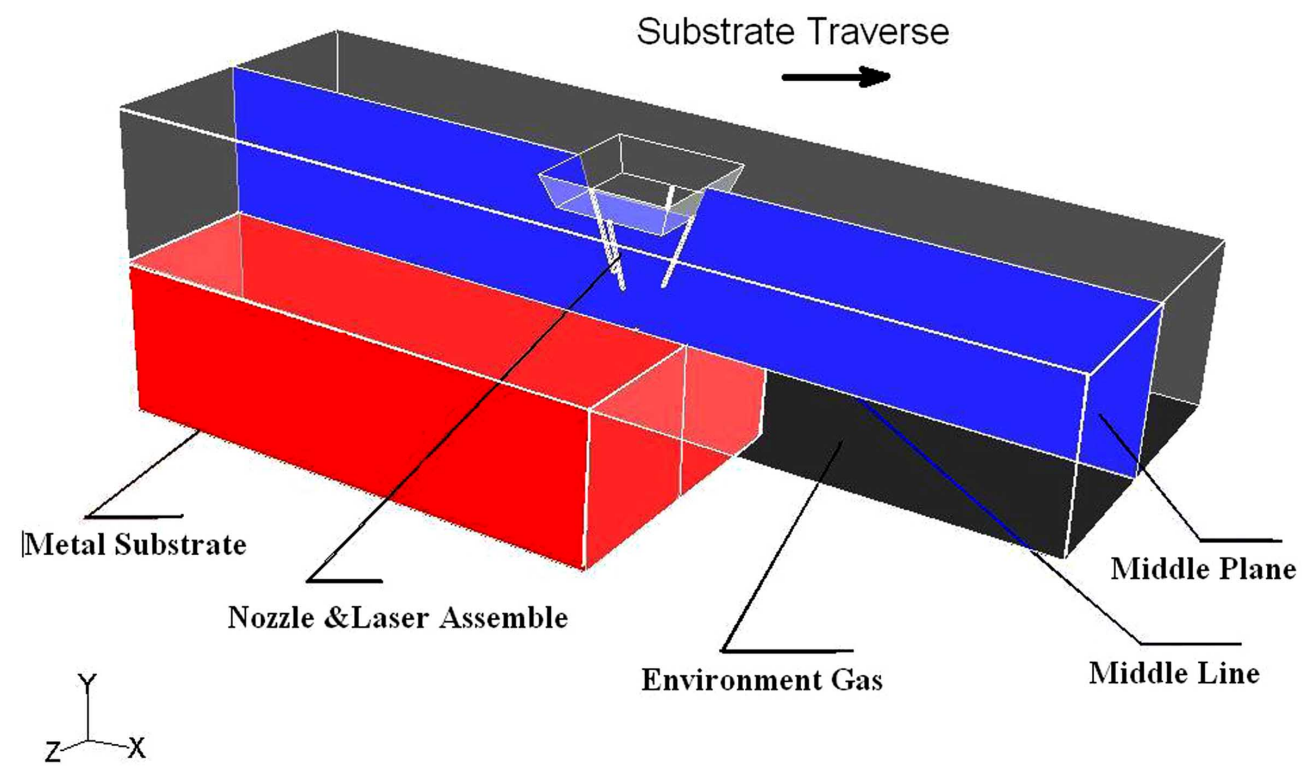

Fig. (1). Real and Simplified LENSTM System.

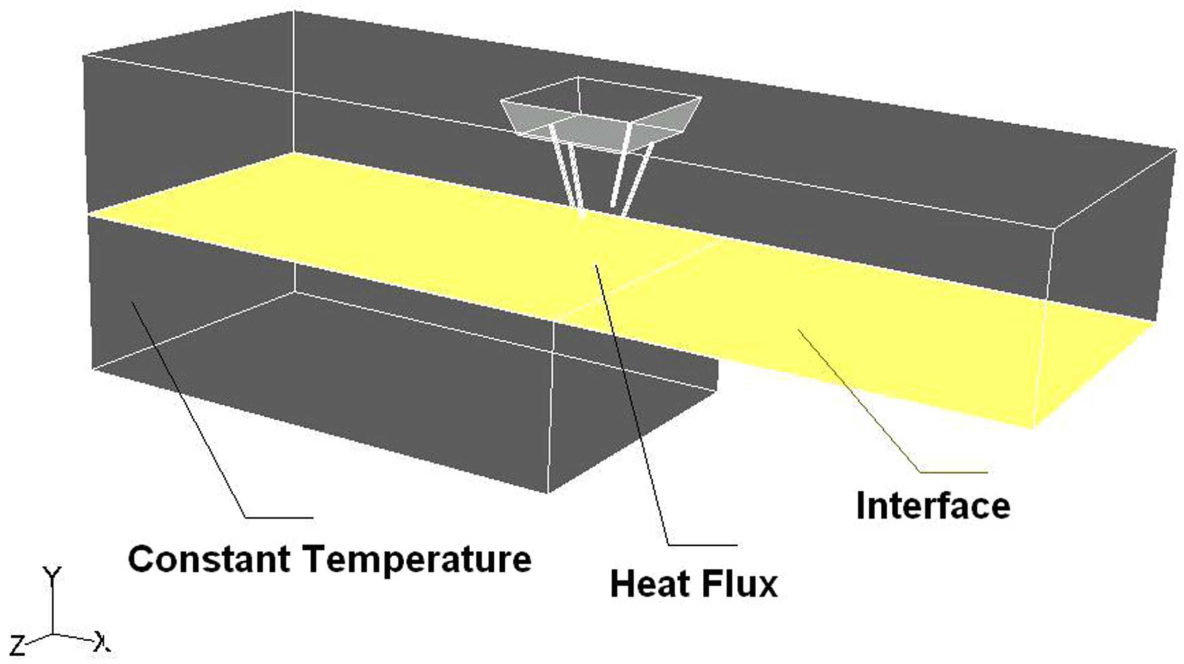

Fig. (2). Boundary Conditions \& Mesh.

fraction of each of the phases is known at each location. Thus the variables and properties in any given cell are either purely representative of one of the phases, or representative of a mixture of the phases, depending upon the volume fraction values.

\section{Mushy Zone Melting / Solidification Model}

The mushy zone is a region in which the liquid fraction $\beta$ lies between 0 and 1 . The mushy zone is modeled as a "pseudo" porous medium in which the porosity decreases from 1 to 0 as the material solidifies. When the material has fully solidified in a cell, the porosity becomes zero and hence the velocities also drop to zero.

$\beta=0$, if; $\mathrm{T}<\mathrm{T}_{\text {solidus }}$

$\beta=1$, if; $\mathrm{T}<\mathrm{T}_{\text {liquidus }}$
$\beta=\frac{\mathrm{T}-\mathrm{T}_{\text {solidus }}}{\mathrm{T}_{\text {liquidus }}-\mathrm{T}_{\text {solidus }}}$, if $\mathrm{T}_{\text {solidus }}<\mathrm{T}<\mathrm{T}_{\text {liquidus }}$

\section{RESULTS AND DISCUSSIONS}

The calculation geometry and the dimensions are shown in Figs (1 and 2), respectively. Notice that in the current experimental setup, both ends of the fiber bundles are extended out of the mold and cooled by two heat sinks at the ends. There are several processing parameters influencing the rate of solidification of the alloy melt containing carbon fibers. These parameters include, but are not limited to, the effect of the pouring temperature of the alloy melt, the heat sink temperature imposed at the ends of the fiber bundle, the length of the fiber that is extending out of the mold, the thermal conductivity of the fibers, the initial temperature of the mold, the conductivity and wall thickness of the mold, the pressure applied during squeeze casting, and also the diameter of the fiber bundle. The results can be utilized to 
Table 1 Simulation Parameters

\begin{tabular}{|c|c|}
\hline Density $\left(\mathbf{K g} / \mathbf{m}^{\wedge} \mathbf{3}\right)$ & $\mathbf{7 7 3 0}$ \\
\hline \hline Specific Heat Cp $(\mathrm{j} / \mathrm{k} / \mathrm{K})$ & 450 \\
\hline Thermal conductivity $(\mathrm{W} / \mathrm{m} / \mathrm{K})$ & 21.5 \\
\hline Viscosity $(\mathrm{Kg} / \mathrm{m} / \mathrm{s})$ & 0.0055 \\
\hline Solids Temperature $(\mathrm{K})$ & 1390 \\
\hline Liquids Temperature $(\mathrm{K})$ & 1440 \\
\hline Laser power $(\mathrm{W})$ & 220 \\
\hline Beam Diameter $(\mathrm{m})$ & 0.0005 \\
\hline Traverse Velocity $(\mathrm{m} / \mathrm{s})$ & 0.0148 \\
\hline Powder Feeding rate $(\mathrm{kg} / \mathrm{s})$ & $3.34 \mathrm{E}$ \\
\hline Powder Injection Velocity $(\mathrm{m} / \mathrm{s})$ & 6.37 \\
\hline Powder Diameter $(\mathrm{m})$ & $1.00 \mathrm{E}-07$ \\
\hline Heat Flux $\left(\mathrm{W} / \mathrm{m}^{\wedge} 2\right)$ & $1.12 \mathrm{E}+09$ \\
\hline Environment Temperature $(\mathrm{K})$ & 320 \\
\hline Environment Pressure $(\mathrm{Pa})$ & 101325 \\
\hline
\end{tabular}

fiber bundle. The results can be utilized to design microstructure of carbon fiber reinforced aluminum matrix composites. Some of the simulation results are validated by the cooling curves obtained from experimental measurements.

This linear increase of solidification times with pouring temperatures is very similar to the simulation results obtained by Zhang et al. [20] in squeeze cast Al alloy/SiCp composites.

This paper simplifies the real LENS system as shown in Fig. (1). The upper stationary part represents the laser \& powder nozzles assemble and the surrounding environmental gas, while the under moving part represents the moving metal substrate. The dimension of upper part is $0.18 m \times 0.06 m \times 0.03 m$ and the dimension of under part is $0.10 m \times 0.06 m \times 0.03 m$.
Table 2. Cases Description

\begin{tabular}{|c|c|c|c|}
\hline & Case 1 & Case 2 & Case 3 \\
\hline \hline VOF Model & $\sqrt{ }$ & & \\
\hline Melting/Solidification Model & $\sqrt{ }$ & $\sqrt{ }$ & \\
\hline Powder Injection Model & $\sqrt{ }$ & & \\
\hline
\end{tabular}

As shown in Fig. (2), the mesh size of the whole model is 480,000 grids. There are heat flux boundary condition exerted on position of laser spot and the value is coming from the calculation of laser power used and laser spot diameter. Powder injections are set on each nozzle and the powder size, flow rate and injection speed is directly from the sample making parameters. The surrounding boundary is to be constant temperature wall, this is reasonable with high precision, because the heat infected zone is small, around 5-10mm [22], this will be verified when the temperature distribution is calculated out.

In this paper, three real samples were studied; correspondingly, three simulations were carried out. The parameters are collected in Table $\mathbf{1}$. In case 1, the powder injection model, VOF model, and Melting/Solidification model were used. In case 2, the powder injection model was taken off from case1, so case 2 did not take the effect of powder's absorption of energy into account. While in the metal was only treated as a solid, so the whole effect of melting pool was get rid of. The cases descriptions are shown in Table 2.

Fig. (3) shows the temperature distribution of three cases along the middle line at time $\mathrm{t}=1 \mathrm{~s}$ separately. The temperature remains unchanged as the environment temperature; only in the small area around laser spot $(x=0 \mathrm{~m})$ the temperature shoots up suddenly.

Fig. (4) shows the temperature changing with time of three cases; from this figure, the heating rate and cooling rate is easy to find. The numerical results and experimental sample results on cooling rate is listed in Table $\mathbf{3}$.

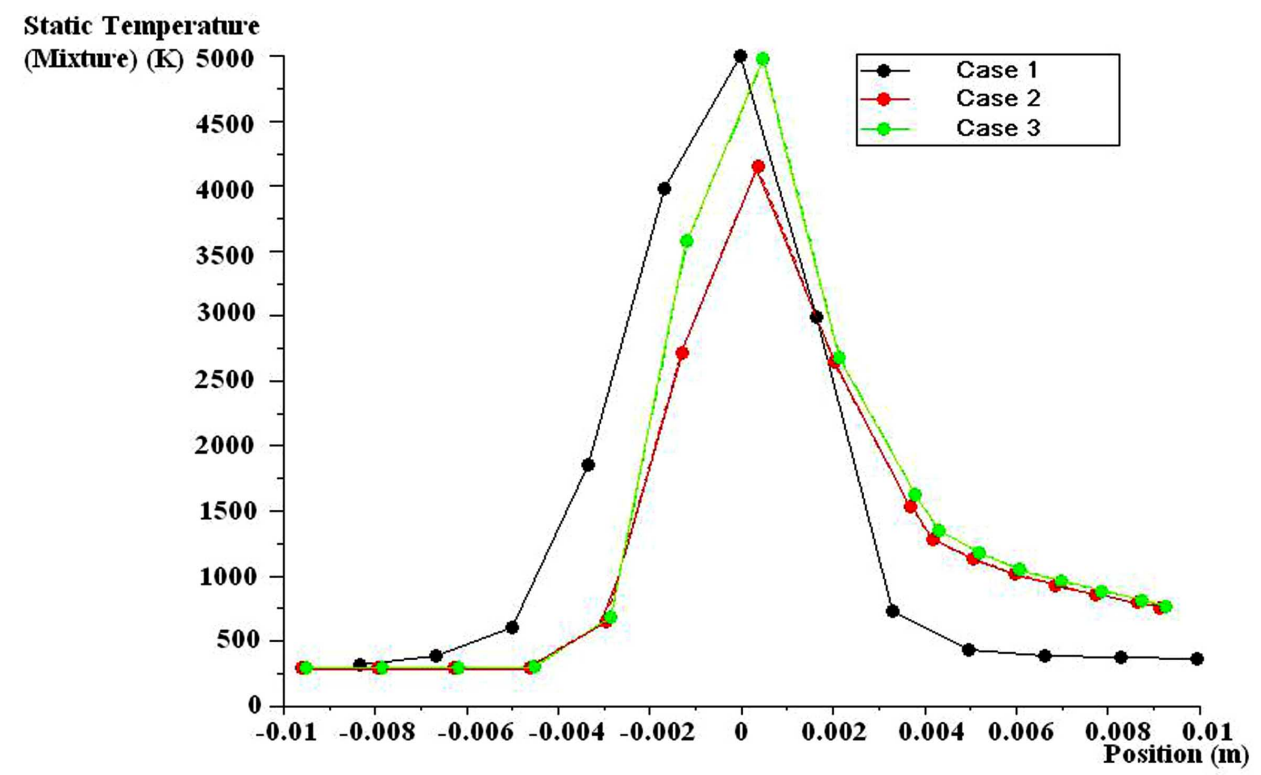

Fig. (3). Temperature Distribution along the middle lone at different time: $t=1 \mathrm{~s}$. 


\section{Cooling Rate}

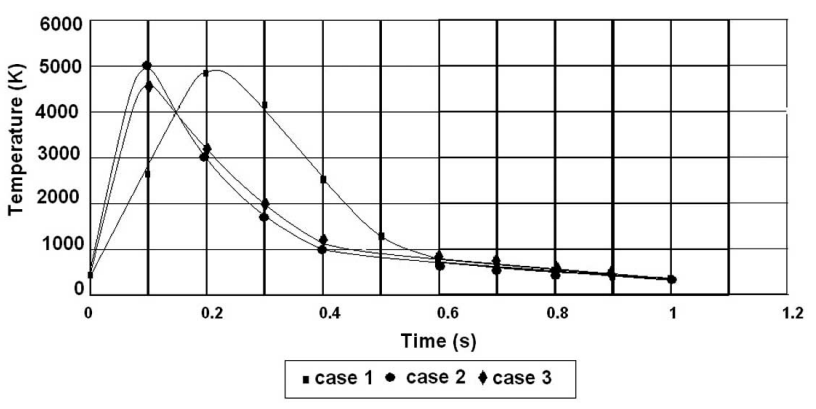

Fig. (4). Temperature Changing with Time.

Table 3. Cooling Rate (K/s)

\begin{tabular}{|c|c|c|}
\hline & Experimental Data & Numerical Data \\
\hline \hline Case 1 & 11000 & 9163 \\
\hline Case 2 & 11000 & 7954 \\
\hline Case 3 & 11000 & 6163 \\
\hline
\end{tabular}

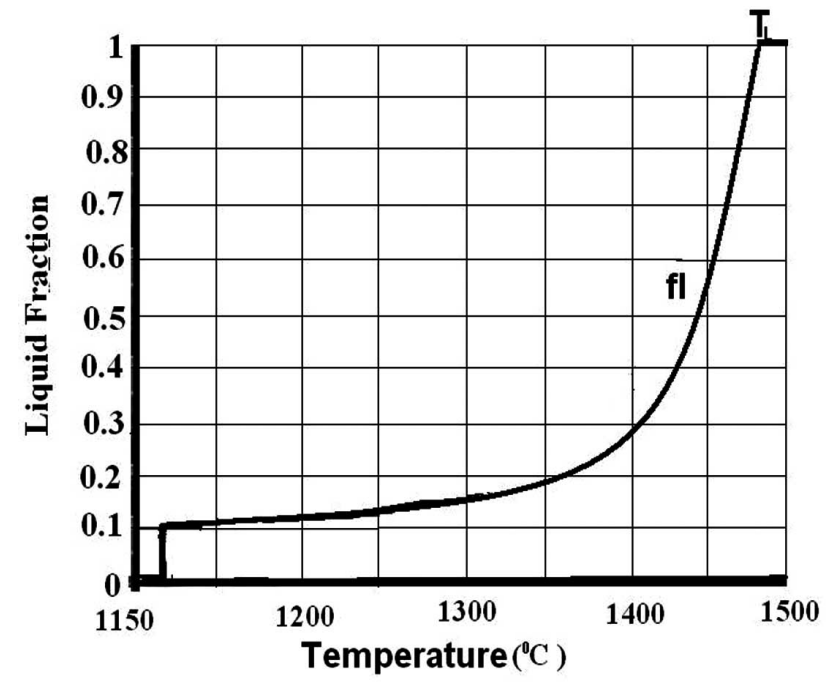

Fig. (A1). The Liquid Fraction-Temperature Curve Following the Schell Relationship of A1-4.5 weight (wt) \%.

Compared with previous work [16], the case 2 yield more accurate results by compared with experimental data for the refined mesh. While in case 2, because the powder injection model was ignored, so as the energy transfer between the powder and continuum metal was ignored, so the final average cooling rate is smaller than the experimental data. In case 3, the melting pool effects was also get rid of, so the results between case 2 and case 3 differ from each other. From the comparison of three cases, the cooling rate largely depends on the metal's solid material properties. At the same time, the powder's injection also contributes much to the final cooling rate.

\section{CONCLUSIONS}

The computational simulation shows that the predictions were made within 16 percent error when compared the cooling rate with the experimental data. The computational model has predicted that the LENS ${ }^{\mathrm{TM}}$ process is capable of incorporating $\mathrm{TiC}$ reinforcement particles into a metal matrix. TiC particles were plated with nickel 1-3 microns thick to facilitate wetting/bonding in the metal matrix. The nickel layer is generally not visible at the particle interface using optical/SEM microscopy. Apparently, the nickel layer has been taken into solution by the $316 \mathrm{~L}$ matrix to varying degrees. No evidence of dewetting is present on particles that do not exhibit the nickel layer. TiC particle were added into the matrix at 1-45 microns in size. The dendritic arm spacing was measured on the order of 5-10 microns. Evidence of particles being entrapped, is evident in the microstructure between cells and groups of cells or dendrites.

The equilibrium solidification phase transformation for 316 L stainless steel is primary ferrite solidification. The microstructure observed was primary austenite indicating a change to the equilibrium solidification mode. Further work can be done to refine to dig out more precise mass transfer between powder and melting pool, so that more precise cooling rate can be measured.

\section{NOMENCLATURE}

\section{English Symbols}

$\begin{array}{lll}a & = & \text { Numerical parameter } \\ E & = & \text { Energy }\left(\mathrm{Jm}^{3} / \mathrm{kg}\right) \\ H & = & \text { Enthalpy }\left(\mathrm{Jm}^{2} / \mathrm{kg} / \mathrm{s}\right) \\ P & = & \text { Pressure }\left(\mathrm{kgm}^{-1} \mathrm{~s}^{-2}\right) \\ Q_{j} & = & \text { Heat } \operatorname{Transfer}(\mathrm{J}) \\ t & = & \text { time }(\mathrm{s}) \\ V_{i} & = & \mathrm{i} \text { component of velocity }(\mathrm{m} / \mathrm{s}) \\ V_{j} & = & \mathrm{j} \text { component of velocity }(\mathrm{m} / \mathrm{s}) \\ X_{j} & = & \text { Cartesian coordinate }(\mathrm{m})\end{array}$

Greek Symbols

$P \quad=\quad$ Density $\left(\mathrm{kg} / \mathrm{m}^{3}\right)$

$\tau_{i j}^{(l)}=\quad$ Laminar Shear Stress Tensor $\left(\mathrm{N} / \mathrm{m}^{2}\right)$

$\tau_{i j}^{(T)}=\quad$ Turbulent Shear Stress Tensor $\left(\mathrm{N} / \mathrm{m}^{2}\right)$

$\lambda_{1}=$ Dentritic Arm Spacing (DAS) (m)

$\varepsilon \quad=\quad$ Cooling Rate $(\mathrm{K} / \mathrm{s})$

\section{CONFLICT OF INTEREST}

None declared.

\section{ACKNOWLEDGEMENT}

This work was supported by US Army.

\section{APPENDIX}

The change of liquid fraction of Al-4.5 weight (wt) $\% \mathrm{Cu}$ alloy can follow different relationships. Among many proposed relationships, the Scheil curve seems to be widely used by other researchers. The authors have chosen to use the Scheil curve for this study; the graph is shown on Fig. (A1). 


\section{REFERENCES}

[1] W.N. Su, P. Erasenthirian, and P.M. Dickens, "Investigation of fully dense laser sintering of tool steel powder using nd:yag (neodymium-doped yttrium aluminum garnet) laser", Mech. Eng. Sci. J., vol. 217, Part(1) C02202, pp. 127-138, 2003.

[2] T .R. Anthony, and H.E. Cline, "Surface rippling induced by surface-tension gradients during laser surface melting and alloying", $J$. Appl. Phys., vol. 48, no. 9, 1977.

[3] Y. Kamotani, and S. Ostrach, "Analysis of velocity data taken in surface tension driven convection experiment in microgravity", Phys. Fluids, vol. 6, no. 11, pp. 1070-6631/94/6(11)3601/9, 1994

[4] P.A. Kobryn, and A.L. Semiatin, "Laser Forming of Ti-6Al-4V: Research Overview", Solid Freeform Fabricat Symposium Proceeding, 2000, pp. 58-65.

[5] W. Liu, and J. DuPont, "Fabrication of titanium aluminide matrix composites by laser engineered net shaping", Solid Freeform Fabricat Symposiam. Procceding, 2002, pp. 124-132.

[6] M. R. Boddu, A. Musti, R. G. Landers, S. Agarwal, and F. W. Liou, "Empirical modeling and vision based control for laser aided metal deposition process", Solid Freeform Fabrication Symposium Proceeding., pp. 452-459.

[7] J. Brooks, C. Robino, T. Headley, S. Goods, and M. Griffith, "Microstructure and property optimization of LENS deposited H13 Tool Steel", Solid Freeform Fabricat. Symposiam. Procceding, 1999, pp. 375-382.

[8] Q.Y. Pan, M. Arsenault, D. Apelian, and M.M. Makhlouf, "SSM processing of $\mathrm{ALB}_{2}$ grain refined Al-Si alloys", AFS Trans, vol. 112, pp. 4-53, 2004.

[9] K. Atwood, "Creating a complex metal part in a day is goal of commercial consortium. sandia national laboratories, sandia corporation", USA, 1997.

[10] A. Gatto, E. Bassoli, L. Luliano, and M.G. Violante, "Rapid casting in the development of an automotive component: evaluation of dimensional performances", Rapid Prototyp. Conference. Procceding., Dearborn, MI, 2005.

[11] A. Henning, S. Grzesiak, R. Toth-Koch, I. Becker, I. Effenberger, and E. Weskämper. "Rapid Prototyping and Manufacturing -
Trends and developments in Germany". Rapid Prototyp Conference Proceeding. Dearborn, MI, 2005.

[12] W.U.H. Syed, A.J. Pinkerton, and L. Li. "A Comparative study of wire feeding and powder feeding in direct diode laser deposition for rapid prototyping". Appl. Surf. Sci. J., vol. 247, pp. 268-276, 2005.

[13] M. Grujicic, Y. Hu, G.M. Fadel, and D.M. Keicher. "Optimization of the LENS Rapid Fabrication Process for In-flight Melting of Feed Powder". J. Mater. Synth. Proc., vol. 9, no. 5, 2002.

[14] W. Hofmeister, M. Griffith, M. Ensz, and J. Smugersky. "Solidification in direct metal deposition by LENS processing". J. Miner. Metals Mater. Soc., vol. 53, no. 9. pp. 30-34, 2001.

[15] N.W. Klingbeil, S. Bontha, C.J. Brown, D.R. Gaddam, P.A. Kobryn, H.L.Fraser, J.W. Sears. Effects of Process Variables and Size Scale on Solidification Microstructure in Laser-Based Solid Freeform Fabrication of Ti-6A1-4V, Proc. Solid Freeform Fabricat. Symposium [15th] August 2-4, 2004, Austin, Texas, Defense Technical Information Center Compilation Part Notice, ADP020465, 2004.

[16] W. Liu, and J. DuPont. "Fabrication of Titanium Aluminide Matrix Composites by Laser Engineered Net Shaping", Solid Freeform Fabricat Symposium Proceeding, pp. 124-132, 2002.

[17] K.G. Watkins. "Achieving the potential of direct fabrication with lasers", $3^{\text {rd }}$ International Conference on Laser Assisted Net Shaping (LANE 2001), Erlagen, 2001, pp. 25-38.

[18] N.W. Klingbeil, C.J. Brown, S. Bontha, P.A. Kobryn, and H.L. Fraser. "Prediction of Microstructure in Laser Deposition of Titanium Alloys", Solid Freeform Fabricat Symposium Proc., Austin, TX, 2002.

[19] X. Zhenyu, R.S. Amano, S.G. Marek, P. Rohatgi. "A Study on Laser Engineered Net Shaping Prototyping Technology", ASME Comp. Info. Eng. Conf., DETC2007-35323, Las Vegas, NV, 2007.

[20] S.V. Patankar, Numerical Heat Transfer and Fluid Flow, McGraw-Hill, New York, 1980.

[21] C.R. Swaminathan, and V.R. Voller. "On the Enthalpy Method". Int. J. Numer. Methods Heat Fluid Flow, vol. 3, pp. 233-244, 1993.

[22] M.L. Griffith, M.T. Ensz. "Understanding the microstructure and properties of components fabricated by LENS". Sandia Nat. Labs, 2000.

(C) Amano et al.; Licensee Bentham Open.

This is an open access article licensed under the terms of the Creative Commons Attribution Non-Commercial License (http://creativecommons.org/licenses/by-nc/3.0/) which permits unrestricted, non-commercial use, distribution and reproduction in any medium, provided the work is properly cited. 